\title{
Eight microsatellite markers for Armillaria cepistipes and their transferability to other Armillaria species
}

\author{
Simone Prospero • Esther Jung • Tetyana Tsykun • \\ Daniel Rigling
}

Accepted: 15 February 2010 /Published online: 7 March 2010

(C) KNPV 2010

\begin{abstract}
We isolated eight polymorphic microsatellite markers for the basidiomycete Armillaria cepistipes and characterised them by analysing 50 isolates representing two geographically distinct populations from Switzerland and the Ukraine. The number of alleles per locus and population varied from one to eight, resulting in 43 alleles over the eight loci and two populations. In both populations, no significant linkage disequilibrium was observed between pairs of loci. Significant $(P<0.05)$ deviations from HardyWeinberg equilibrium were observed at one locus in the Swiss population and at three loci in the Ukrainian population. Of the eight loci developed for $A$. cepistipes, six were also polymorphic in $A$. gallica, four in $A$. ostoyae, two in A. mellea, and one in A. borealis. Beside the potential to be used for population genetic studies on $A$. cepistipes, these microsatellites thus represent additional molecular markers for three of the four annulated Armillaria species occurring in Europe.
\end{abstract}

S. Prospero $(\bowtie) \cdot$ E. Jung $\cdot$ T. Tsykun $\cdot$ D. Rigling

WSL Swiss Federal Research Institute,

Zuercherstrasse 111,

8903 Birmensdorf, Switzerland

e-mail: simone.prospero@wsl.ch

T. Tsykun

Uzhhorod National University,

88000 Uzhhorod, Ukraine
Keywords Simple sequence repeats - Genetic diversity · Polymorphism · Cross-species amplification

\section{Introduction}

Microsatellites or simple sequence repeats (i.e. stretches of repeated motifs of 2-6 bases) are increasingly replacing other types of molecular markers in studies on conservation biology, evolutionary genetics, and molecular ecology (Goldstein and Schlötterer 2001). The main advantages of microsatellites include a wide distribution in eukaryotic genomes, co-dominance (i.e. in diploid organisms, the alleles on both chromosomes are revealed), assumed neutrality, high levels of length polymorphism, high levels of accuracy and reproducibility, and relative ease of use (Jarne and Lagoda 1996).

The genus Armillaria (Tricholomataceae, Basidiomycota) is an important natural component of the mycoflora of many forest ecosystems worldwide. All Armillaria species can survive saprotrophically on woody substrates (e.g. roots, debris, and stumps), contributing significantly to wood decomposition and mineral cycling (Kile et al. 1991). In addition, Armillaria species may produce extensive and persistent networks of rhizomorphs (i.e. filamentous aggregations of hyphae) in forest soils. Except for some species that are obligate saprotrophs, most Armillaria 
species are primary or secondary/opportunistic pathogens (Gregory et al. 1991). In Europe, five annulated Armillaria species are currently known (i.e. A. mellea, A. ostoyae, A. gallica, A. cepistipes, and A. borealis), which differ in geographical and ecological distribution, host range, and pathogenicity (Guillaumin et al. 1993). Frequently, different Armillaria species coexist sympatrically in the same forest stand (Prospero et al. 2003; Keča et al. 2009). In mixed mountainous coniferous forests in Central Europe, A. cepistipes is the most widespread rhizomorph-producing Armillaria species (Legrand et al. 1996; Rigling et al. 1998). This species, which also occurs in North America (Kim et al. 2006) and Asia (Ota et al. 1998), is considered to be preferentially saprotrophic and only a secondary/opportunistic pathogen (Prospero et al. 2004). Despite its wide distribution and ecological importance, no neutral genetic markers are presently available for $A$. cepistipes. In this study, we developed and characterised polymorphic microsatellite markers

Table 1 Characterisation (repeat motif, primer sequences, GenBank accession number, allele size range) of eight polymorphic microsatellite loci from Armillaria cepistipes in Switzerland and Ukraine

\begin{tabular}{|c|c|c|c|c|c|c|c|c|c|c|c|c|c|}
\hline \multirow[t]{2}{*}{ Locus } & \multirow{2}{*}{$\begin{array}{l}\text { Repeat } \\
\text { motif }\end{array}$} & \multirow[t]{2}{*}{ Primer sequences $\left(5^{\prime}-3^{\prime}\right)$} & \multirow{2}{*}{$\begin{array}{l}\text { GenBank } \\
\text { Accession } \\
\text { No. }\end{array}$} & \multicolumn{5}{|c|}{ Swiss population $(N=25)$} & \multicolumn{5}{|c|}{ Ukrainian population $(N=25)$} \\
\hline & & & & $\begin{array}{l}\text { Allele } \\
\text { size (bp) }\end{array}$ & $N_{\mathrm{A}}$ & $H_{\mathrm{O}}$ & $H_{\mathrm{E}}$ & $H W E$ & $\begin{array}{l}\text { Allele } \\
\text { size (bp) }\end{array}$ & $N_{\mathrm{A}}$ & $H_{\mathrm{O}}$ & $H_{\mathrm{E}}$ & $H W E$ \\
\hline Arm02 & $(\mathrm{CA})_{\mathrm{n}}$ & $\begin{array}{l}\text { F: FAM-ATCGGAGAAG } \\
\text { AAGCCAGACC } \\
\text { R: AGGCAGGACATCG } \\
\text { AGTTGAG }\end{array}$ & GQ153965 & $168-172$ & 3 & 0.44 & 0.52 & NS & $162-176$ & 5 & 0.32 & 0.49 & 0.001 \\
\hline Arm05 & $(\mathrm{GTC})_{\mathrm{n}}$ & $\begin{array}{l}\text { F: FAM-GAGGAAGAGC } \\
\text { TACGCACAGG } \\
\text { R: CGGTTTCATCGGA } \\
\text { GGTCTA }\end{array}$ & GQ153966 & $226-238$ & 5 & 0.56 & 0.53 & NS & $226-238$ & 5 & 0.68 & 0.68 & NS \\
\hline Arm09 & $\begin{array}{l}(\mathrm{GTT})_{\mathrm{n}} \\
(\mathrm{CTG})_{\mathrm{n}}\end{array}$ & $\begin{array}{l}\text { F: } H E X \text {-CGTCTCTGGTC } \\
\text { CATGAAGGT } \\
\text { R: GCCTCAGCAGCAC } \\
\text { CAGAT }\end{array}$ & GQ153967 & $178-196$ & 7 & 0.58 & 0.76 & 0.02 & $181-199$ & 7 & 0.76 & 0.84 & NS \\
\hline Arm11 & $(\mathrm{CAG})_{\mathrm{n}}$ & $\begin{array}{l}\text { F: FAM-CATCCCTTTCG } \\
\text { GACAGCAC } \\
\text { R: TACCAGTCCATCTG } \\
\text { GCATGA }\end{array}$ & GQ153968 & $158-167$ & 4 & 0.60 & 0.68 & NS & $152-167$ & 6 & 0.68 & 0.62 & NS \\
\hline Arm13a & $(\mathrm{GTC})_{\mathrm{n}}$ & $\begin{array}{l}\text { F: } H E X \text {-TGTTCGTGACAG } \\
\text { CATTGGAT } \\
\text { R: TCTGCCTCTGAGGA } \\
\text { ACTTCG }\end{array}$ & GQ153969 & $158-162$ & 2 & 0.22 & 0.20 & NS & $158-168$ & 4 & 0.25 & 0.53 & 0.006 \\
\hline Arm 15 & $\begin{array}{l}(\mathrm{GAC})_{\mathrm{n}} \\
\cdots \\
(\mathrm{GAC})_{\mathrm{n}}\end{array}$ & $\begin{array}{l}\text { F: FAM-CGAGCCGTCAA } \\
\text { CAGAGAATC } \\
\text { R: TCCCCAAACACAA } \\
\text { CCTTCTC }\end{array}$ & GQ153970 & $175-185$ & 2 & 0.04 & 0.12 & NS & 185 & 1 & 0 & NA & NA \\
\hline Arm16 & $(\mathrm{TCG})_{\mathrm{n}}$ & $\begin{array}{l}\text { F: } H E X \text {-ATTTGGAATCC } \\
\text { TGACGTTGC } \\
\text { R: GGCGCATTTGGTCA } \\
\text { AAGTAA }\end{array}$ & GQ153971 & $137-155$ & 7 & 0.84 & 0.80 & NS & $137-158$ & 8 & 0.80 & 0.81 & NS \\
\hline Arm17 & $(\mathrm{TCG})_{\mathrm{n}}$ & $\begin{array}{l}\text { F: } F A M-G G G A A C G T A A T C \\
\text { AACGTCCA } \\
\text { R: AGTACGGGGATGGAA } \\
\text { AGACC }\end{array}$ & GQ153972 & $241-250$ & 4 & 0.42 & 0.64 & NS & $238-250$ & 5 & 0.46 & 0.70 & 0.009 \\
\hline
\end{tabular}

$N_{\mathrm{A}}$, number of alleles observed; $H_{\mathrm{O}}$, observed heterozygosity; $H_{\mathrm{E}}$, Nei's (1978) expected heterozygosity ( $N A$ not applicable at the specific locus); HWE, Fisher's exact test for Hardy-Weinberg equilibrium ( $N S$ not significant at $P>0.05 ; N A$ not applicable at the specific locus) 
for A. cepistipes and tested their transferability to the other four annulated Armillaria species occurring in Europe. Since Armillaria species have a life cycle with a persistent diploid vegetative stage (Guillaumin et al. 1991), co-dominant microsatellite markers are particularly suited for population genetic studies on this genus.

Genomic DNA was extracted from twelve Swiss isolates of $A$. cepistipes grown on $1 \%$ malt extract using a CTAB-chloroform-isopropanol protocol (Gardes and Bruns 1993). Prior to microsatellite development, these DNA samples were pooled. A library was then constructed by Ecogenics $\mathrm{GmbH}$ (Zurich, Switzerland) from size selected genomic DNA ligated into SAULA/SAULB-linker (Armour et al. 1994) and enriched by magnetic bead selection with biotin-labelled $(\mathrm{GT})_{13},(\mathrm{CT})_{13},(\mathrm{GCT})_{9}$, and $(\mathrm{CGT})_{8}$ oligonucleotide repeats (Gautschi et al. $2000 \mathrm{a}, \mathrm{b})$. Of the 528 recombinant colonies screened, 195 gave a positive signal after hybridization. Plasmids from 89 positive clones were sequenced and sequences were searched for the presence of microsatellite inserts. Out of these 89 sequences, 67 were discarded because either the microsatellite stretches or the flanking regions were too short, or the sequences were homologous to each other. For the remaining 22 loci, we used PRIMER3 version 0.4.0 (http://frodo.wi.mit.edu/; Rozen and Skaletsky 2000) to design specific forward and reverse PCR primers with a melting temperature $\mathrm{T}_{\mathrm{m}}$ between 57 and $63^{\circ} \mathrm{C}$, which enabled us to amplify one or two fragments of 100-300 bp in length for each locus. Each forward primer was labelled at the 5 '-end with a fluorescent dye (i.e. 6-FAM-blue or HEX-green) for detection on a capillary sequencer. All loci were amplified using a PCR program of 1 cycle of $95^{\circ} \mathrm{C}$ for $15 \mathrm{~min}$, followed by 30 cycles of $94^{\circ} \mathrm{C}$ for $30 \mathrm{~s}, 58^{\circ} \mathrm{C}$ for $90 \mathrm{~s}$, and $72^{\circ} \mathrm{C}$ for $90 \mathrm{~s}$, and a final elongation of $72^{\circ} \mathrm{C}$ for $30 \mathrm{~min}$. Fluorescent multiplex PCR reactions were performed in $10 \mu \mathrm{L}$ volumes containing: 1X Multiplex PCR Master Mix (Qiagen), $0.1 \mu \mathrm{M}$ of each primer, and $1 \mu 1$ DNA (10-50 ng). PCR products were scored for successful amplification on $1.5 \%$ agarose gels and subsequently sized on an ABI 3130 sequencer (Applied Biosystems, Foster City, USA) using ROX400 size standard (Applied Biosystems). Results were analysed with GENEMAPPER (Applied Biosystems) and genotyping was repeated for isolates with unclear allelic patterns.
The 22 primer pairs were initially tested for successful amplification and polymorphism on a set of seven A. cepistipes isolates collected throughout Switzerland. Based on somatic incompatibility tests (Worrall 1997), these seven isolates represented seven different genotypes. Eight primer pairs that were polymorphic among the seven A. cepistipes isolates were subsequently used to screen 50 isolates from two different geographic populations for allelic variation. Twenty-five isolates were collected in mixed coniferous forests in Switzerland (Rigling et al. 1998; Prospero et al. 2004) and 25 isolates in an area of about 10,000 ha of beech (Fagus sylvatica) forests in the Carpathian Biosphere Reserve in Ukraine. All isolates were recovered from rhizomorphs and were considered to be diploid (Guillaumin et al. 1991). Standard genetic parameters (i.e. number of alleles observed, observed heterozygosity and Nei's (1978) expected heterozygosity) were estimated using GENEPOP version 3.4 (Raymond and Rousset 1995). For each locus, deviation from Hardy-Weinberg equilibrium was tested by conducting a Fisher's exact test, with unbiased $P$-values estimated with a Markov chain method (10,000 dememorisations, 20 batches, 5,000 iterations per batch) implemented in GENEPOP. An exact test (10,000 dememorisations, 20 batches, 5,000 iterations per batch) was conducted with GENEPOP in order to test for linkage disequilibrium among pairs of loci.

Table 2 Cross-species PCR amplification of eight polymorphic microsatellite loci (Table 1), specifically developed for Armillaria cepistipes, in four other Armillaria species

\begin{tabular}{lllll}
\hline $\begin{array}{l}\text { Microsatellite } \\
\text { loci }\end{array}$ & A. gallica & A. ostoyae & A. borealis & A. mellea \\
\hline Arm02 & $\mathrm{p}$ & - & - & - \\
Arm05 & $\mathrm{p}$ & $\mathrm{p}$ & $\mathrm{p}$ & $\mathrm{m}$ \\
Arm09 & - & $\mathrm{p}$ & \pm & \pm \\
Arm11 & $\mathrm{p}$ & $\mathrm{m}$ & $\mathrm{m}$ & $\mathrm{p}$ \\
Arm13a & $\mathrm{p}$ & - & - & - \\
Arm15 & $\mathrm{p}$ & $\mathrm{p}$ & $\mathrm{m}$ & - \\
Arm16 & $\mathrm{p}$ & $\mathrm{p}$ & \pm & $\mathrm{p}$ \\
Arm17 & - & - & - & - \\
\hline
\end{tabular}

-, no PCR product; \pm , unclear, weak, or inconsistent PCR product; $\mathrm{m}$, locus monomorphic in the tested set of isolates; $\mathrm{p}$, locus polymorphic in the tested set of isolates 
To test for the transferability of the newly developed markers to closely related Armillaria species, all eight polymorphic primer pairs of $A$. cepistipes were tested for successful amplification and polymorphism on a set of seven Swiss isolates (representing seven different genotypes based on somatic incompatibility tests) of each of the four additional annulated Armillaria species that are commonly found in European forests, i.e. A. gallica, A. ostoyae, A. mellea, and $A$. borealis. Primer pairs that proved to be polymorphic among the seven isolates per species were used to assess allelic variation (i.e. number of alleles observed, observed heterozygosity and expected heterozygosity) in 17-29 widely scattered Swiss isolates of each Armillaria species.

In A. cepistipes, 13 out of the 22 primer pairs successfully amplified PCR products of the expected size but three were monomorphic across the analysed set of isolates and two produced amplicons whose quality was too poor for further analyses (i.e. multibanding patterns, inconsistent amplification). In $A$. cepistipes, we detected a total of 43 alleles over the eight polymorphic microsatellite loci, ranging from one allele at locus Arm15 (population Ukraine) to eight alleles at locus Arm16 (population Ukraine; Table 1). Although the Arm13a locus was polymorphic, it consistently showed no PCR amplicons in 16 out of 50 isolates (Swiss population: seven out of 25; Ukrainian population: nine out of 25). This problem, which could be due to a frequent mutation in the primer site, could not be solved by redesigning the primers. Therefore, locus Arm 13a may be only partially useful for population analyses. In both populations, no significant linkage disequilibrium was observed in all cases $(P>0.05)$. Observed and expected (Nei 1978) heterozygosities per locus only showed a significant $(P<0.05)$ deviation from Hardy-Weinberg equilibrium for locus Arm09 in the Swiss population and for loci Arm02, Arm13a, and Arm17 in the Ukrainian population (Table 1). This difference between the two populations may be a consequence of random sampling effects due to small population sizes.

Of the eight polymorphic loci in A. cepistipes, one (A. borealis) to six (A. gallica) were also polymorphic in the other tested Armillaria species (Table 2). At these loci, allele sizes were in the same ranges as observed in A. cepistipes (Table 3). The number of alleles per locus varied from two to seven, resulting in 32 different alleles over the seven loci and the four

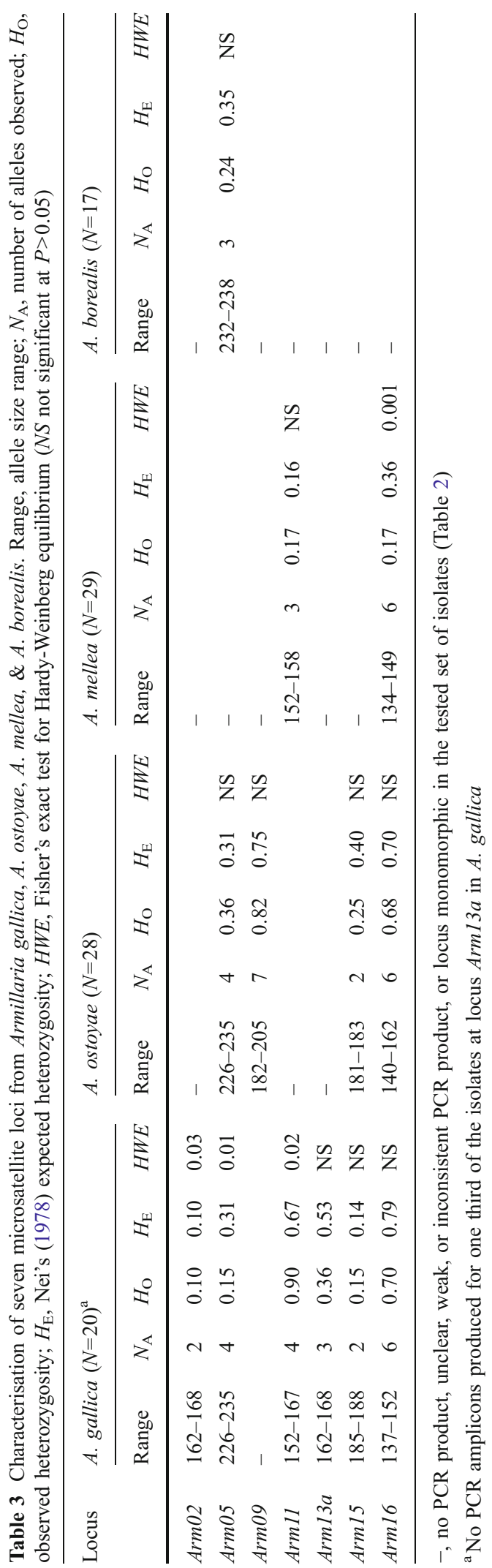


Armillaria species. Significant linkage disequilibrium was observed between loci Arm05 and Arm16 in A. ostoyae $(P=0.008)$ and between loci Arm13a and Arm16 in A. gallica $(P=0.02)$. Since in A. cepistipes no significant linkage among loci was observed, the loci are most likely also not physically linked in the other Armillaria species. The significant linkage between two loci detected in A. ostoyae and $A$. gallica may result from various causes apart from physical linkage, such allelic dropout, null alleles, or random sampling effects (Selkoe and Toonen 2006). Both minimal and maximal observed and expected heterozygosities per locus were detected in A. gallica (Table 3). Three loci (Arm02, Arm05 and Arm11) in A. gallica and one locus (Arm16) in A. mellea showed significant $(P<0.05)$ deviations from Hardy-Weinberg equilibrium. As observed for A. cepistipes, the PCR failed to amplify the loci Arm13a in about one third of the A. gallica isolates.

The new polymorphic microsatellite loci should be very useful for population genetic studies (e.g. population structure, gene flow, phylogeography) of $A$. cepistipes. Moreover, they constitute additional markers to those already published in other Armillaria species (Baumgartner et al. 2009 for A. mellea; Lefrançois et al. 2002 for A. gallica; Langrell et al. 2001 and Worrall et al. 2004 for A. ostoyae). The different rates of inter-species transferability probably reflect phylogenetic relationships among the five annulated Armillaria species present in Europe. For example, previous genetic studies have shown that $A$. cepistipes is genetically close to $A$. gallica (Keča et al. 2006; Kim et al. 2006), which might explain why six of the eight polymorphic loci developed for $A$. cepistipes were also polymorphic in A. gallica.

Acknowledgements We thank R. Holderegger for critical comments on the manuscript and the Competence Center Environment and Sustainability (CCES) of the ETH domain for financial support (project GEDIHAP).

\section{References}

Armour, J. A., Neumann, R., Gobert, S., \& Jeffreys, A. J. (1994). Isolation of human simple repeat loci by hybridization selection. Human Molecular Genetics, 3, 599-605.

Baumgartner, K., Grubisha, L. C., Fujiyoshi, P., Garbelotto, M., \& Bergemann, S. (2009). Microsatellite markers for the diploid basidiomycete fungus Armillaria mellea. Molecular Ecology Resources, 9, 943-946.
Gardes, M., \& Bruns, T. D. (1993). ITS primers with enhanced specificity for basidiomycetes - application to the identification of mycorrhizae \& rusts. Molecular Ecology, 2, 113118.

Gautschi, B., Tenzler, I., Müller, J. P., \& Schmid, B. (2000a). Isolation and characterization of microsatellite loci in the bearded vulture (Gypaetus barbatus) and cross-amplification in three Old World vulture species. Molecular Ecology, 9, 2193-2195.

Gautschi, B., Widmer, A., \& Koella, J. (2000b). Isolation and characterization of microsatellite loci in the Dice Snake (Natrix tessellate). Molecular Ecology, 9, 2191-2193.

Goldstein, D. B., \& Schlötterer, C. (Eds.). (2001). Microsatellites. Evolution and applications. New York: Oxford University Press.

Gregory, S. C., Rishbeth, J., \& Shaw, C. G., III. (1991). Pathogenicity and virulence. In C. G. Shaw \& G. A. Kile (Eds.), Armillaria root disease (pp. 76-87). Washington: USDA Forest Service.

Guillaumin, J.-J., Anderson, J. B., \& Korhonen, K. (1991). Life cycle, interfertility, and biological species. In C. G. Shaw \& G. A. Kile (Eds.), Armillaria root disease (pp. 10-20). Washington: USDA Forest Service.

Guillaumin, J.-J., Mohammed, C., Anselmi, N., Courtecuisse, E., Gregory, S. C., Holdenrieder, O., et al. (1993). Geographical distribution and ecology of the Armillaria species in Western Europe. European Journal of Forest Pathology, 23, 321-341.

Jarne, P., \& Lagoda, P. J. L. (1996). Microsatellites, from molecules to populations and back. Trends in Ecology and Evolution, 11, 424-429.

Keča, N., Bodles, W. J. A., Woodward, S., Karadžić, D., \& Bojovic, S. (2006). Molecular-based identification and phylogeny of Armillaria species from Serbia and Montenegro. Forest Pathology, 36, 41-57.

Keča, N., Karadžić, D. \& Woodward, S. (2009). Ecology of Armillaria species in managed forests and plantations in Serbia. Forest Pathology (in press) doi:10.1111/j.14390329.2008.00578.x.

Kile, G. A., McDonald, G. I., \& Byler, J. W. (1991). Ecology and disease in natural forests. In C. G. Shaw \& G. A. Kile (Eds.), Armillaria root disease (pp. 102-121). Washington: USDA Forest Service.

Kim, M.-S., Klopfenstein, N. B., Hanna, J. W., \& McDonald, G. I. (2006). Characterization of North American Armillaria species: genetic relationships determined by ribosomal DNA sequences and AFLP markers. Forest Pathology, 36, 145-164.

Langrell, S. R. H., Lung-Escarmant, B., \& Decrooc, S. (2001). Isolation and characterization of polymorphic simple sequence repeat loci in Armillaria ostoyae. Molecular Ecology Notes, 1, 305-307.

Lefrançois, J.-B., Lung-Escarmant, B., \& Langrell, S. R. H. (2002). Development of novel polymerase chain reaction (PCR) based microsatellite markers in Armillaria gallica by cross-amplification and species-specific cloning. Molecular Ecology Notes, 2, 182-184.

Legrand, P., Ghahari, S., \& Guillaumin, J.-J. (1996). Occurrence of genets of Armillaria spp. in four mountain forests in central France: the colonization strategy of Armillaria ostoyae. New Phytologist, 133, 321-332. 
Nei, M. (1978). Estimation of average heterozygosity and genetic distance from a small number of individuals. Genetics, 89, 583-590.

Ota, Y., Matsushita, N., Nagasawa, E., Terashita, T., Fukuda, K., \& Suzuki, K. (1998). Biological species of Armillaria in Japan. Plant Disease, 82, 537-543.

Prospero, S., Holdenrieder, O., \& Rigling, D. (2003). Primary resource capture in two sympatric Armillaria species in managed Norway spruce forests. Mycological Research, 157, 329-338.

Prospero, S., Holdenrieder, O., \& Rigling, D. (2004). Virulence of Armillaria cepistipes and Armillaria ostoyae on four Norway spruce provenances. Forest Pathology, 34, 1-14.

Raymond, M., \& Rousset, F. (1995). GENEPOP (version 1.2): population genetics software for exact tests and ecumenicism. Journal of Heredity, 86, 248-249.

Rigling, D., Blauenstein, H., Walthert, L., Rigling, A., Kull, P., Schwyzer, A., et al. (1998). Rhizomorph producing
Armillaria species in Norway spruce stands in Switzerland. In C. Delatour, J.-J. Guillaumin, B. Lung-Escarmant, \& B. Marçais (Eds.), Root and butt rots of forest trees (pp. 259-265). Paris: INRA Editions.

Rozen, S., \& Skaletsky, H. J. (2000). PRIMER3 on the www for general users and for biologist programmers. In $\mathrm{S}$. Krawetz \& S. Misener (Eds.), Bioinformatics methods and protocols: Methods in molecular biology (pp. 365386). Totowa: Humana.

Selkoe, K. A., \& Toonen, R. J. (2006). Microsatellites for ecologists: a practical guide to using and evaluating microsatellite markers. Ecology Letters, 9, 615-629.

Worrall, J. J. (1997). Somatic incompatibility in basidiomycetes. Mycologia, 89, 24-36.

Worrall, J. J., Sullivan, K. F., Harrington, T. C., \& Steimel, J. P. (2004). Incidence, host relations and population structure of Armillaria ostoyae in Colorado campgrounds. Forest Ecology and Management, 192, 191-206. 